\title{
ORGANIC COLOURING AGENTS IN THE PHARMACEUTICAL INDUSTRY
}

\author{
Šuleková, M. ${ }^{1}$, Smrčová, M. ${ }^{1}$, Hudák, A. ${ }^{1}$ \\ Heželová, M. ${ }^{2}$, Fedorová, M. ${ }^{3}$ \\ ${ }^{1}$ Department of Chemistry, Biochemistry and Biophysics, Institute of Pharmaceutical Chemistry \\ University of Veterinary Medicine and Pharmacy, Komenského 73, 04181 Košice \\ ${ }^{2}$ Faculty of Metallurgy, Institute of Recycling Technologies \\ Technical University in Košice, Letná 9, 04200 Košice \\ ${ }^{3}$ Department of Pharmacy and Social Pharmacy \\ University of Veterinary Medicine and Pharmacy, Komenského 73, 04181 Košice \\ Slovakia
}

alexander.hudak@uvlf.sk

\section{ABSTRACT}

Food dyes are largely used in the process of manufacturing pharmaceutical products. The aim of such a procedure is not only to increase the attractiveness of products, but also to help patients distinguish between pharmaceuticals. Various dyes, especially organic colouring agents, may in some cases have a negative impact on the human body. They are incorporated into pharmaceutical products including tablets, hard gelatine capsules or soft gelatine capsules, lozenges, syrups, etc. This article provides an overview of the most widely used colouring agents in pharmaceuticals, their characteristics and the EU legislation which regulates their use.

Key words: analysis; food dye; legislation; pharmaceutical product; potential health risk

\section{INTRODUCTION}

In addition to the active ingredients, various additives are used in the manufacture of pharmaceuticals. This group of compounds includes dyes. A colour additive is any dye, pigment, or other substance that imparts colour to food, drink or any non-food applications including pharmaceuticals. Moreover, a colour additive is also any chemical compound that reacts with another substance and causes the formation of a colour $[22,56]$. The pharmaceutical industry employs various inorganic and, especially, organic dyes for this purpose. These colour additives are pigments of natural origin or synthetic chemical compounds. However, most of the dyes obtained from natural sources are unstable and can easily undergo degradation during the processing of pharmaceutical products. Therefore, dyes of synthetic origin are widely used, not only because of their stability, but also given the low cost of production when compared to natural dyes [66].

The priority of the dye is to increase the aesthetic appearance of the pharmaceutical products. It can be said that 
the dyes are the cosmetics for the pharmaceutical products [2]. Dyes are added to nutritional supplements and pharmaceutical products for commercial, psychological and practical purposes. A variety of coloured tablets, capsules (hard gelatin, soft gelatin), syrups and multivitamin supplements are attracted by children precisely because of their appearance. Colouring of pharmaceuticals improves their easy identification already at the first sight. Various colours of drugs also help distinguish different strengths of the same drug, which can eliminate faults of an over dose or under dose. Synthetic dyes are organic substances that may interact with the human body. These interactions are a potential health risk, especially when they are consumed excessively [51]. There have been various studies focused on neurotoxicity [54], genotoxicity [53] and carcinogenicity [41] of synthetic dyes. The relationship between dyes and the children's attention deficit disorder (ADD), attention-deficit hyperactivity disorder (ADHD), immune system problems, and certain allergic reactions have also been examined. Due to the fact that the results of various researches have been ambiguous, nowadays, a great deal of attention is paid to study the effects of artificial dyes on human health.

\section{EUROPEAN UNION LEGISLATION ON DYES}

Dyes belong to one of the most important classes of pharmaceutical excipients that can affect the health of certain population groups. Therefore, the basic purpose of any laws related to drugs and substances must be the safety of public health. To ensure this task various measures are taken. They protect the health without hindering the development of the pharmaceutical industry and trade with pharmaceuticals. Practical experience so far has shown that in terms of health, there is no reason to disallow the use of foodstuff dyes also in pharmaceutical products.

For this reason, the basic legislation determining the use of dyes in food have in the past, but also currently, overlapped with the legislation on pharmaceutical products and medicines. The first collection of international food standards and guidelines called Codex Alimentarius (CA) was issued in 1962 by the Food and Agriculture Organisation (FAO) and the World Health Organization (WHO) [11]. The Codex Committee on Food Additives and Contaminants (CCFAC) operates as part of the CA [35]. The Com- mittee focuses on food additives and contaminants, and implements recommendations for the maximum permitted limits for the use of individual food additives. Codex Alimentarius and WHO/FAO have produced a database in which evidence of the biological activity of food additives are collected, the so called General Standards for Food Additives (GSFA).

Dyes are included as a specific part in the group of additives, because as early as in the Council Directive of 23 October 1962 [17], a list was established of colouring materials authorized for use in foodstuffs intended for human consumption. The basic rule focused on the approximation of the laws of the Member States relating to the colouring materials which may be added to medicinal products under Council Directive 78/25/EEC of 12 December 1977 [18]. In Article 1 of this Directive, it is stated that Member States shall not authorize, for the colouring of medicinal products for human and veterinary use, any colouring materials than those covered by Annex I, Sections I and II, to the Directive of 1962, as subsequently amended. The Directive joined the applicable requirements to food dyes with the requirements applicable to pharmaceutical products. The document, however, did not contain any specific references to earlier legislation that was subsequently cancelled. On the 30th of June 1994, the European Parliament and Council Directive 94/36/EC adopted the use of dyes in food [19], outlining a single list of colouring agents to be used in foodstuffs. The specific purity criteria concerning dyes for the use in foodstuffs were laid down in the Directive 95/45/EC of 26 July 1995 [13]. It can be said that this document essentially replaced the provisions of the Directive of 1962. Directive 2009/35/EC of the European Parliament and of the Council of 23 April 2009 on the colouring materials which may be added to medicinal products [20]. It states that the primary purpose of any laws concerning medicinal products must be to safeguard the public health. In the introduction of the Directive, in point No. 5 , it is mentioned that experience has shown that there is no reason, on health grounds, why the colouring materials authorised for use in foodstuffs should not also be authorised for use in medicinal products. Therefore, Annex I to Directive 94/36/EC, as well as the Annex to Commission Directive 95/45/EC of 26 July 1995, should also apply to medicinal products. In Article 1 of that document, it states that Member States shall not authorize, for the colouring of medicinal products for human and veterinary use, any colouring materials, those covered 
by Annex I to the Directive 94/36/EC. Legislation relating to the dyes change over time, evolves and adapts.

Based on new research and studies, the appropriateness of the use of certain dyes in pharmaceutical products and their maximum levels are always reviewed. For example, the Scientific Committee on Medicinal Products and Medical Devices adopted an opinion on the suitability and safety of Amaranth, Erythrosine, Canthaxanthin, aluminum and silver as the dyes for medicinal products [61]. Regulation (EC) No 178/2002 of the European Parliament and of the Council of 28 January 2002 [21] laid down the general principles and requirements of food law, established the European Food Safety Authority and laid down procedures in matters of food safety. In compliance with this Regulation, additives used in the EU must be first reviewed by the European Food Safety Authority (EFSA), in accordance with the European Commission. EFSA conclusions are based on the recommendations of the Codex Committee on Food Additives and Contaminants (CCFAC). The EFSA publishes, what is officially known as "Scientific Opinion" in the EFSA Journal, on request from the European Commission. The content of the EFSA Scientific Opinion comprises these subject-matters: technical and chemical characteristics of the dye; description of the manufacturing process; analytical methods used for the determination; chemical reactivity with food; summary of the current authorization for use; dose range, toxicokinetic information; toxicological data; carcinogenicity, genotoxicity, developmental and reproductive toxicity; and hypersensitivity to the substance. Approval of the use of these additives depends on the level of scientific knowledge at the time. Therefore, it is necessary to carry out regular reviews and revisions of legislation with respect to new scientific information in evaluating the conditions of a particular use of additives. In 2008, the European Parliament and Council published Regulation (EC) No 1333/2008 on food additives [14]. In this document, it states that food additives which were permitted before 20 January 2009 shall be subject to a new risk assessment carried out by the EFSA. The commission Regulation (EU) No 257/2010 of 25 March 2010 [15] set up a programme for the re-evaluation of approved food additives in accordance with Regulation (EC) No 1333/2008 of the European Parliament and of the Council on food additives. Considering the above, we can conclude that in practice it is very important to monitor the development of legislation particularly in the field of using the synthetic organic dyes. These rules reflect the new findings on the impact of additive substances on the human body and so help to protect human health.

Given the fact that the European Parliament is wellaware and informed of possible children's health issues linked to the consumption of synthetic dyes, it compiled a bordereau of food dyes allowed to be used in processed food, yet requiring a warning indication in the form of a label on food packaging. Despite this scientific advice, since July 2010, the Annex V of the Regulation (EC) No. $1333 / 2008$ of the European Parliament and of the Council of 16 December 2008 on food additives, provides a list of food dyes (E110, E104, E122, E129, E102, E124) which must provide labels with the following information for target users: may have an adverse effect on activity and attention in children [32].

The toxicological effects of synthetic dyes are concentration-dependent [44]. Given their toxicity, mostly when consumed in excess, synthetic dyes are strictly governed by applicable legislation, regulations and acceptable daily intake (ADI) values for pharmaceuticals safety. The ADI values and eventual health effects on humans for the most commonly used pharmaceutical dyes are listed in Table 1 [16]. The ADI values are listed in units of $\mathrm{mg}$ per $\mathrm{kg}$ of body weight.

\section{THE DYES MOST FREQUENTLY USED IN PHARMACEUTICAL INDUSTRY}

Every product intended for a medical purpose is an elaborate system of active substances and excipients. In recent time, by virtue of the accelerated growth of the eagerness to make commercially attractive products in the pharmaceutical industry, the human body assembles more and more synthetic molecules. In the composition of medicines to the organisms, arrive excipients such as dyes, among which synthetic dyes are prevalent nowadays. Aspects that affect colour stability include: light, oxidising and reducing agents, heat, $\mathrm{pH}$, microbial contamination, and solubility limits. The synthetic dyes have important technological superiority when being compared to most natural dyes given the fact that: they give vivid colours, they are resistant to light, oxidants and reducing agents impact, to $\mathrm{pH}$ changes and they are also less susceptible to various types of impacts that a material is subject to during the technological process. 
Table 1. Acceptable daily intake values and potential health effects on humans for the most commonly used pharmaceutical dyes

\begin{tabular}{ccc}
\hline $\begin{array}{c}\text { Pharmaceutical } \\
\text { dyes }\end{array}$ & $\begin{array}{c}\text { ADI } \\
{\left[\mathrm{mg} \cdot \mathrm{kg} \mathrm{bw}^{-1} \mathrm{day}^{-1}\right]}\end{array}$ & $\begin{array}{c}\text { Potential health effects } \\
\text { on humans }\end{array}$ \\
\hline
\end{tabular}

Tartrazine appears to cause the highest percentage of allergic and intolerance reactions of all the azo

E102,

Tartrazine

7.5 dyes, particularly among asthmatics and those with an aspirin intolerance. The use of Tartrazine in susceptible patients has been reported to lead to allergic or adverse reactions, such as urticaria, eczema, asthma and hyperactive behaviour. Reported cases of hypersensitivity, and hyperkinetic activity in children $[23,34,60]$.

E104,

Quinoline Yellow

0.5

E110,

Sunset Yellow

1.0

\section{E120,}

Cochineal, carminic acid,

Carmines

\section{E122,}

Azorubine, Carmoisine

4.0

5.0

A Quinoline Yellow allergy is an adverse reaction by the body's immune system to a yellow food colouring called Quinoline Yellow which is used in a number of pharmaceuticals. The specific symptoms can vary considerably amongst patients and may range from mild to severe. For this dye, there was some evidence of carcinogenic activity and genotoxicity. E104 causes allergy symptoms in people who are allergic to aspirin. Its consumption after taking aspirin can cause hives, wheezing, sneezing or itching. E104 may result in increased hyperactivity in children $[26,48,55]$.

Gastrointestinal intolerance, with abdominal pain, vomiting, and indigestion, has been associated with sunset yellow. In one case, eosinophilia and hives were present as well. Sunset Yellow may cause allergic or intolerance reactions in certain people. E110 causes side effects such as a hives, allergies, kidney tumours, chromosomal damage, hyperactivity, abdominal pain, nausea and vomiting. E110 may have an adverse effect on activity and attention in children [4, 27].

The natural colourings used, carmine or cochineal extract, can cause allergic reactions. It has been known to cause severe allergic reactions and anaphylactic shock in some people. The hyperactive Children's Support Group recommends that the dye be eliminated from children's diets $[6,65]$.

Azorubine has shown no evidence of mutagenic or carcinogenic properties. E122 may have an adverse effect on the activity and attention in children. It may rarely cause skin and respiratory reactions in susceptible individuals, even at the approved dose [28].

Because Amaranth is an azo dye, it has been proven to provoke asthma, urticaria, rhinitis, eczema and

E123,

Amaranth

0.15 hyperactivity as well as allergic reactions, similar to nettle rash, among asthmatics and individuals who are sensitive to aspirin. Amaranth is considered very dangerous as it increases hyperactivity in affected children [29].
0.7

May increase hyperactivity in affected children. Can adversely affect those that are sensitive to aspirin $[38,50]$.

This substance has been found to have tumorigenic effects in experimental animals, as well as mutagenic effects in both experimental animals and humans. Furthermore, risks include: irritation of eyes,

$$
\text { E127, }
$$

Erythrosine skin, digestive tract, and respiratory tract in its undiluted form. There is a potential risk of negative influences on the thyroid gland due to the fact that E129 has four iodine atoms [3].

\begin{tabular}{lll}
\hline $\begin{array}{l}\text { E129, } \\
\text { Allura Red }\end{array}$ & 7.0 & $\begin{array}{l}\text { Allura Red may cause allergic reactions (e.g. urticaria, asthma), especially when administered in mixes } \\
\text { with other synthetic colour additives [67]. }\end{array}$ \\
\hline $\begin{array}{l}\text { E131, } \\
\text { Patent Blue }\end{array}$ & 5.0 & Several reports of serious allergic or anaphylactic reaction to Patent Blue have been published [71]. \\
\hline $\begin{array}{l}\text { E132, } \\
\text { Indigo Carmine }\end{array}$ & 5.0 & $\begin{array}{l}\text { Indigo Carmine is harmful to the respiratory tract if swallowed. It is also an irritant to the skin and eyes } \\
{[42] .}\end{array}$ \\
\hline $\begin{array}{l}\text { E133, } \\
\text { Brilliant Blue }\end{array}$ & $\begin{array}{l}\text { It has the capacity for inducing an allergic reaction in individuals with pre-existing moderate asthma } \\
{[30] .}\end{array}$ \\
\hline $\begin{array}{l}\text { E151, } \\
\text { Brilliant Black BN }\end{array}$ & $\begin{array}{l}\text { It is one of the colourants that the Hyperactive Children's Support Group recommends be eliminated } \\
\text { from the diet of children. It appears to cause allergic or intolerance reactions, particularly amongst } \\
\text { those with aspirin intolerance. It is a histamine liberator, and may worsen the symptoms of asthma [48]. }\end{array}$ \\
\hline
\end{tabular}


The European Union has authorised 43 dyes as food additives out of which each one was assigned an E-number. Out of these, 17 are synthetic dyes and 26 are either naturally derived, synthesized to match the naturally occurring counterparts, or are inorganic pigments occurring freely in nature in respective amounts [24].

As a category of the additives in the pharmaceutical industry, dyes are commonly classified as either natural or synthetic. For the most part, synthetic dyes have a higher tinctorial strength than natural dyes. Furthermore, synthetic dyes are predominantly water-soluble, relatively stable and not easily destroyed during the drug processing. These aspects, together with their advantageous price, render synthetic dyes more widely used worldwide these days. However, taking toxicological studies into account, the eventual risks of numerous synthetic azo dyes to human health have been found and are of concern. Scientists interested in this particular field of study have discovered that Amaranth starting at a certain concentration can induce dose-related DNA damage in the mouse colon after oral administration. In addition to the genotoxicity, a part of synthetic dyes can also cause allergic or asthmatic reactions for sensitive people, as well as frequent headaches and children's hyperactivity. To prevent the abuse of synthetic dyes, the permissible type and usage of synthetic dyes are strictly regulated in many countries [51].

There are many different classifications of pharmaceutical coloring agents. One of the most useful ways is to simply divide the colours into water-soluble (dyes) and waterinsoluble (pigments) [61].

According to another method of separation, the pharmaceutical colourants are divided into [2]:

1. Organic dyes and their lakes

2. Inorganic or mineral colours

3. Natural colours or vegetable and animal colours

\section{Organic dyes and their lakes}

Organic dyes are synthetic chemical compounds that show intense colouring. They have a wide range of shades of greater colour intensity than natural dyes. They are easier to access and cheaper than natural dyes.

In 1984, FAO/WHO classified synthetic dyes into five major chemical groups: the azo compounds, quinophthalone, triarylmethane group, indigo dyes, and xanthenes. The synthetic dyes are used primarily in their water-soluble form, which is as their sodium, calcium, potassium or ammonium salts. Occasionally, they are used in the form of insoluble lakes, which are produced by precipitating the water-soluble forms onto an alumina or titanium dioxide base. Azo dyes are depicted as having an azo linkage, i.e. a nitrogen-tonitrogen double bond $(-\mathrm{N}=\mathrm{N}-)$. Chemically, in their molecules, one may discover benzene and naphthalene rings joined by azo linkages and containing sulfonic acid groups. Dyes in this group are the azo dyes Azorubine, Amaranth, Sunset Yellow, Tartrazine, Ponceau $4 \mathrm{R}$ and Allura red. The members of triarylmethane dyes are based on a central triphenylmethane structure and are substituted amine derivatives, with or without sulphuric acid groups. The dyes in this class pharmaceutically used are Brilliant Blue and Patent Blue. The members of xanthene dyes are based chemically on a xanthenes nucleus, for instance Erythrosine. Quinophathalone dyes are based on the naphthalene-quinone structure. From the pharmaceutical perspective, Quinoline Yellow is the constituent of this group. Quinoline Yellow is a mixture of salts, principally the mono- and disulfonate. The group of indigoid dyes stems from indigo which has two isatin molecules joined by a double bond. From the pharmaceutical perspective, the most commonly used dye in this class is Indigo Carmine $[31,59]$.

Generally, the colouring agents used in commerce have trivial denominations and there are often several synonyms for each substance. The colourants that we mainly resort to for colouring tablets, capsules and lozenges are synthetic water-soluble dyes, pigments (especially the pacifying agent titanium dioxide) and certain dyes of natural origin (cochineal). These dyes are often used as a dye in the manufacturing of pharmaceuticals: E102 Tartrazine, E104 Quinoline Yellow, E110 Sunset Yellow FCF, E120 - Cochineal, carminic acid, Carmines, E122 Azorubine (Carmoisine), E123 Amaranth, E124 Ponceau 4R (Cochineal Red A), E127 Erythrosine, E129 Allura Red, E131 Patent Blue, E132 Indigo Carmine (Indigotine), E133 Brilliant Blue, and E151 Brilliant Black BN. The dyes that can be contained in pharmaceuticals are detailed in a corresponding directive and are listed in Table 2.

Lakes have been defined by the FDA as the "Aluminum salts of FD\&C water soluble dyes extended on a substratum of alumina". Lakes, unlike dyes, are insoluble and colour by dispersion. Their colour ability depends on particle size. Smaller particles have greater dyeing ability. They are prepared by reacting synthetic dyes with alumina in an aqueous medium [14]. 
Table 2. European Union list of the most commonly used pharmaceutical synthetic dyes

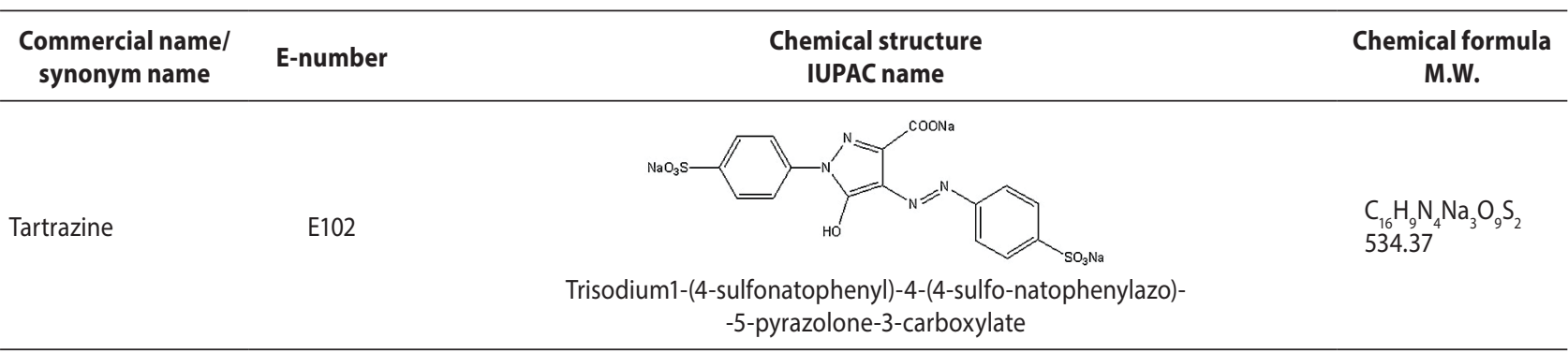

Quinoline Yellow

E104

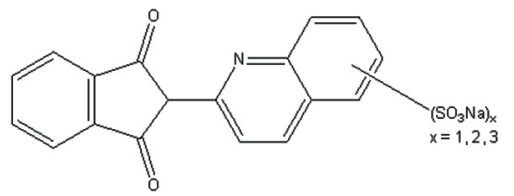
$\mathrm{C}_{18} \mathrm{H}_{9} \mathrm{NNa}_{2} \mathrm{O}_{8} \mathrm{~S}_{2}$ 477.38

Disodium 2-(1,3-dioxoindan-2-yl)quinoline disulfonate

Sunset Yellow FCF

E110
E122

Amaranth

E123

Ponceau 4R/

Cochineal Red A

E124

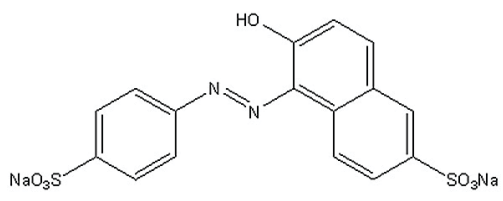

Disodium 6-hydroxy-5-[(4-sulfophenyl)azo]-2-naphthalene-sulfonate<smiles></smiles>

$$
\mathrm{C}_{20} \mathrm{H}_{12} \mathrm{~N}_{2} \mathrm{Na}_{2} \mathrm{O}_{7} \mathrm{~S}_{2}
$$$$
502.44
$$

Disodium4-hydroxy-2-[(E)-(4-sulfonato-1-naphthyl)diazenyl] naphthalene-1-sulfonate

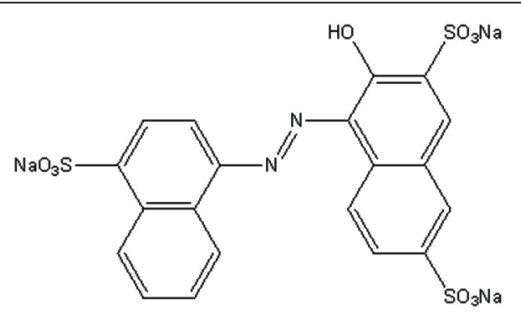

Trisodium (4E)-3-oxo-4-[(4-sulfonato-1-naphthyl) hydrazono] naphthalene-2,7-disulfonate

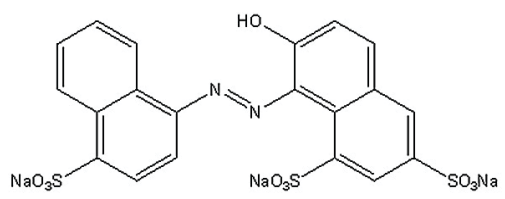
$\mathrm{C}_{20} \mathrm{H}_{11} \mathrm{~N}_{2} \mathrm{Na}_{3} \mathrm{O}_{10} \mathrm{~S}$

Trisodium (8Z)-7-oxo-8-[(4-sulfonatonaphthalen-1-yl) hydrazinylidene] naphthalene-1,3-disulfonate

37 


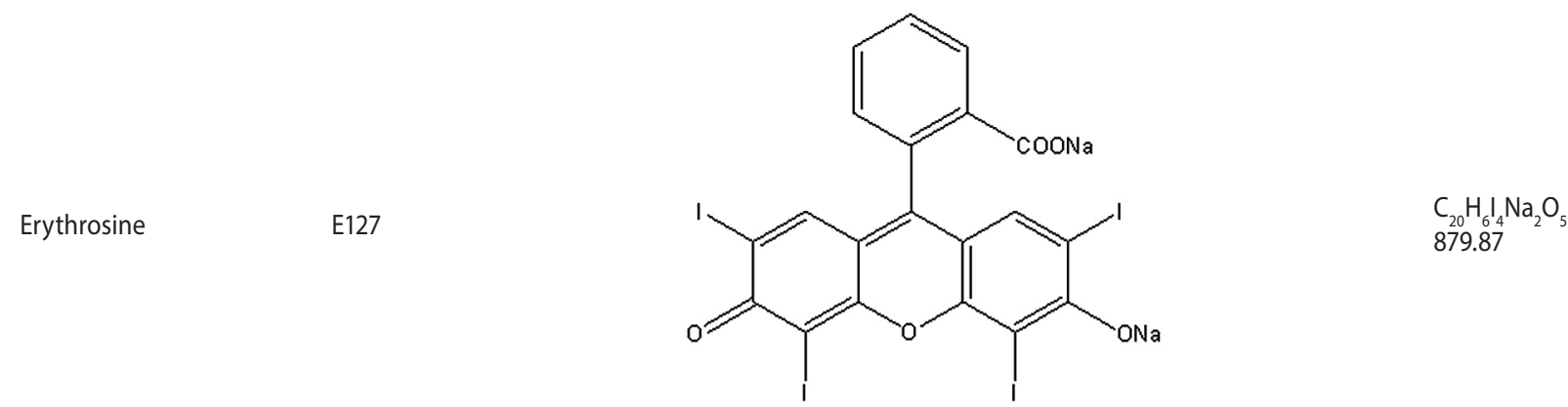

2-(6-Hydroxy-2,4,5,7-tetraiodo-3-oxo-xanthen-9-yl) benzoic acid

Allura Red

E129

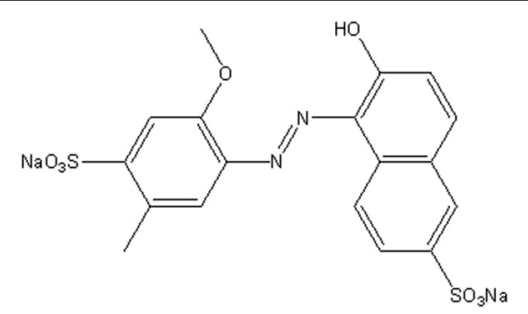

Disodium 6-hydroxy-5-[(2-methoxy-5-methyl-4-sulfophenyl)azo]-
Patent Blue

E131<smiles>CCN(CC)c1ccc(C(=C2C=CC(=[N+](CC)CC)C=C2)c2cc(O)c(S(=O)(=O)O)cc2S(=O)(=O)O)cc1</smiles>

$\mathrm{C}_{18} \mathrm{H}_{14} \mathrm{~N}_{2} \mathrm{Na}_{2} \mathrm{O}_{8} \mathrm{~S}_{2}$ 496.42

2-[(4-diethylaminophenyl)(4-diethylimino-2,5-cyclohexadien-1-ylidene) methyl]-4-hydroxy-1,5-benzene-disulfonate

Indigo Carmine/ Indigotine<smiles>CS(=O)(=O)c1ccc2c(c1)C(=O)/C(=C1/Nc3ccc([N+](=O)[O-])cc3C1=O)N2</smiles>

$\mathrm{C}_{27} \mathrm{H}_{3} \mathrm{~N}_{2} \mathrm{O}_{7} \mathrm{~S}_{2}$

579.71

Disodium salt 3,3'-dioxo-2,2'-bis-indolyden-5,5'-disulfonic acid

Brilliant Black BN Ethyl-[4-[[4-[ethyl-[(3-sulfophenyl)methyl]amino]phenyl]-(2 - sulfophenyl)




\section{Natural colours or vegetable and animal colours}

Among natural dyes we include substances with different chemical structures and various physicochemical properties. They are obtained by extraction from different parts of plants, trees or animal products. Some of these colours are the products of chemical synthesis rather than extraction from a natural source, for example, $\beta$-carotene of commerce is regularly synthetic in origin. The term "synthetic in origin" frequently applied to such materials is "nature identical", which in many ways is more descriptive.

In general, natural dyes are less stable to light, heat and certain $\mathrm{pH}$ values than other dye groups. The ability to colour natural products is easier and more readily available than synthetic dyes. They do, however, have an advantage in that they have a wide acceptability [2]. The most commonly used colours in pharmaceutical products are from this group of colours: caramel, cochineal, riboflavin, anthocynins, annato and curcumin. In terms of possible adverse effects on humans, the cohineal is the one that gets the most attention.

Cochineal dye is obtained from the dried bodies of female Dactylopius coccus Costa insects (Cochineal) by extraction with water, alcohol or aqueous alcoholic solution. The main component of cochineals is anionic anthraquinone glycoside, carmine acid (7- $\alpha$-D-glycopyranosyl9,0-dihydro-3,5,6,8-tetrahydroxy-1-methyl-9,10-dioxo2-anthracene-carboxylic acid). The molecular structure (Figure 1a) consists of an anthraquinone chromophore, a sugar residue, and a carboxyl group. Carmine is the finished aluminium/calcium lake of carminic acid, and is the commercial dye (E120) used to produce colour to food or pharmaceuticals. The possible structural formula for the aluminium complex of carminic acid is shown in Figure $1 \mathrm{~b}$. Both carminic acid and carmine are reasonably stable against light, heat and oxidation. Carminic acid is orange at a $\mathrm{pH}$ lower than 5 and bluish-red over 8 . A variety of shades from yellow-red to near blue are possible. The solubility of carmine preparations varies depending on the nature of the cations present. Products where the major cation is ammonium (ammonium carminate) are freely soluble in water at $\mathrm{pH} 3.0$ and $\mathrm{pH}$ 8.5. Products where the major cation is calcium (calcium carminate) are only slightly soluble in water at $\mathrm{pH}$ 3.0, but freely soluble at $\mathrm{pH}$ 8.5.

Carmine is used to colour different types of food, beverages, drugs and cosmetics. Increased amounts can cause allergic reactions, childhood hyperactivity and skin tumors in sensitive individuals. Increased hyperactivity has been reported in a few cases. The Hyperactive Children's Support Group recommends that the dye be eliminated from children's diets. As the colourant is of animal origin, it is not acceptable for use in foods or medicinal products for vegans [73].<smiles>Cc1c(C(=O)O)c(O)cc2c1C(=O)c1c(O)c([C@H]3O[C@H](CO)[C@@H](O)[C@H](O)[C@H]3O)c(O)c(O)c1C2=O</smiles>

a)

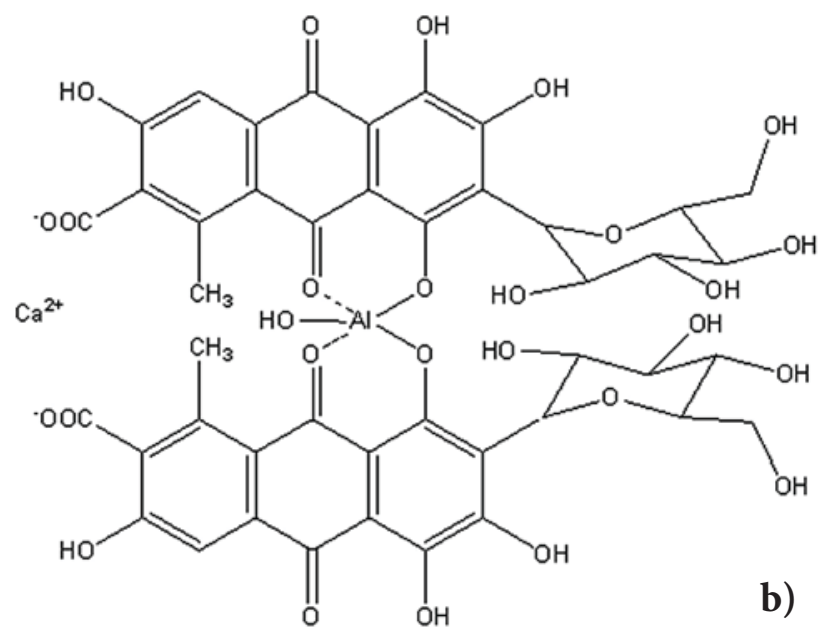

Fig. 1. a) Carminic acid; b) Carmine - possible structural formula for the aluminium complex of carminic acid

\section{Inorganic or mineral colours}

Inorganic colours, metal oxides, hydroxides or sulphides are used in particular. These substances are characterized by their stability to light and some are opaque materials. The range of colours we can achieve with these substances is less than that of organic colourings. Today, mainly yellow and red iron oxides (E172) are used to dye medicines. Titanium dioxide (E170) is used to colour and opacify hard gelatin capsules. 


\section{POTENTIAL HEALTH EFFECTS OF SYNTHETIC DYES ON HUMANS}

An extensive amount of dyes are employed in the area of pharmaceutical manufacturing. The official concession to make use of the synthetic dyes in the pharmaceutical industry is subjected to a wide spectrum of toxicity tests and extremely stringent legislative provisions in all developed states. The crucial chemical structure of artificial dyes consists of azo group and aromatic rings which may be of toxic effects to human health, mainly in cases when they have been over consumed by patients and by pharmaceutical clients in general on a daily basis. In the light of these facts, the producers are obliged to enumerate such ingredients on medicinal packaging to help people avoid potential adverse effects. Most synthetic coloured additives are carcinogenic, teratogenic and are the cause of allergic reactions. Toxicology studies are routinely conducted on an ongoing basis by official institutions - responsible authorities such as the World Health Organisation (WHO), the Food and Drug Administration (FDA), and the European Commission (EC). The outcome of this continuous review is that the various regulatory bodies around the world have compiled lists of permitted colours that are generally viewed as being free from serious adverse, undesired toxicological effects [51].

Some of the groups of dyes have been associated with suspected adverse effects. In 2007, a study scrutinising the use of six dyes (Tartrazine, Quinoline Yellow, Sunset Yellow, Azorubin, Ponceau 4R and Allura Red) was published. The study results connected these dyes to behaviour issues in children. Nonetheless, after reviewing the outcomes of the study, the European Food Standards Agency came to the conclusion that no legislative change or amendment was in fact required [61].

A study by the Food Standards Agency (FSA) in 2007 demonstrated that the consumption of food in which certain dyes were present could potentially negatively influence hyperactive behaviour in children in that they would cause responses that can involve many aspects ranging from excessive movement, to speech and attentiveness. The study focused on three-year-old and eight to nine-year-old children who were given three different types of beverages to drink. Consequently, their behaviour was evaluated by the teachers and their parents. This study, published in 2007 in The Lancet, indicated that the commonly used ar- tificial food colourings may in fact exacerbate hyperactive behaviour in young individuals. On the basis of such investigations, the involved researchers recognised that hyperactive behaviour in children increased with products containing artificial colouring additives. They concluded that the results demonstrated an adverse effect on the behaviour in the sample of individuals after consumption of the food dyes. Recently, it has also been reported that artificial dyes may result in negative impacts on the children's: attention deficit disorder (ADD), immune system problems and certain allergic reactions. Attention Deficit Hyperactivity Disorder (ADHD), represented, for example, by low tolerance to frustration, impulsivity, and inattention, is one of the most widespread behavioral disorders in children. These disorders have symptoms that may begin in childhood and continue into adulthood. ADHD symptoms may be a reason of or directly launch problems at home, school, work and in relationships. Asthmatic symptoms, which include coughing, wheezing and chest tightness, are commonly seen in an asthma attack. Thanks to appropriate treatments for symptoms of asthma, both children and adults are given an opportunity to live a standard, quality of life. Among common causes of allergic symptoms caused by the use of pharmaceuticals, we may enumerate, among others, allergies due to the incorporated dyes $[38,50]$.

\section{DETERMINATION OF DYES IN PHARMACEUTICALS}

Sample preparation constitutes a very important step in order to achieve reliable pharmaceutical analysis, but in general, it is not given sufficient attention. The main pharmaceuticals that are dyed are [61]:

Tablets: either the core itself or the coating.

Hard or soft gelatine capsules: the capsule shell or coated beads.

Oral liquids.

Topical creams and ointments.

For this reason, conventional sample processing techniques are directed to these different dosage forms. Sample preparation can involve a number of steps including: dispersion, particle size reduction (e.g. milling, grinding and homogenization), solubilisation of the target to be analysed, derivatization, sample clean-up (e.g. removing the undesirable interferences), and clarification (e.g. removing insoluble materials). The necessary sample preparation 
steps are selected with regard to the particular dosage form and analysis techniques used $[10,58]$. The most developed technique is the process usually used for the preparation of solid dosage forms (tablets, capsules). It consists of four basic steps:

1. Grinding

2. Extraction

3. Dilution and

4. Filtration.

When the filtration is non-effective due to the very fine particles of the tablets, centrifugation is recommended. It is a simple procedure for dosage forms that are immediately released. Additional clean-up of a sample is typically not needed which is advantageous in terms of the time of sample preparation [10]. The commercial market offers a large number of automated systems for implementation of various sample preparation actions. Those systems are usually designed in such a way to minimize the possibility of contamination or loss of sample during the preparation steps [52]. The specific procedure for processing the sample of a drug in determining dyes depends on: its form, the number of dyes to be determined, and the analytical method to be used for the determination.

Up to now, a variety of methods for separation, identification and determination of dyes have been suggested. For the purpose of quantification of the dye content in the pharmaceutical products and food, modern analytical methods and techniques are currently used, such as follows: high performance liquid chromatography (HPLC) $[39,40,43,46,47,51,64,70,74]$, ion-pair liquid chromatography (IP-LC) $[9,36]$, thin-layer chromatography (TLC) $[5,49,63]$, spectrometry, derivative spectrometry, and spectrophotometric methods [7, 57, 62, 68]. Electroanalytical methods also find its application in this field; mainly adsorptive voltammetry [1] and differential pulse polarography $[8,12]$.

The behavior of the Carmine (E120) was studied by square-wave adsorptive stripping voltammetry (SW-AdSV) at the hanging mercury drop electrode. It was observed that Carmine gave a sensitive stripping voltammetric peak at $-350 \mathrm{mV}$ in $\mathrm{pH} 3$ acetate buffer. The SW-AdSV peak currents depended linearly on the concentration of Carmine from $5 \times 10^{-8}$ to $1.25 \times 10^{-7}$ mol.dm ${ }^{-3}(r=0.99)$. A detection limit of $1.43 \times 10^{-9}$ mol.dm ${ }^{-3}$ with RSD of $2.2 \%$ and a mean recovery of $97.9 \%$ were obtained.
The differential pulse polarography method was applied for the determination of Carmoisine (E122), Ponceau 4R (E124) and Allura Red (E129) in soft drinks and sweets. They can be easily distinguished from natural dyes, which are not electroactive, using differential pulse polarography. The recovery was in the

$96-105 \%$ range and the relative standard deviation was close to $1 \%$ for the three dyes. The limits of quantification in the polarographic cell, estimated from the polarographic data, were 42,43 and $34 \mu \mathrm{g} \cdot \mathrm{dm}^{-3}$ for Carmoisine, Allura red and Ponceau 4R, respectively [8].

Jaworska et al. [37] reported a comprehensive research in which the detection and separation conditions for the analysis of 15 synthetic dyes (E102, E104, E110, E120, E122, E123, E124, E127, E128, E129, E131, E132, E133, E142 and E151) by micellar electrokinetic capillary chromatography were examined. A large amount of commercially available pharmaceuticals of different dosage forms (coated tablet, film-coated tablet, hard/soft capsule, syrup etc.) were tested during this study. Coated and film-coated tablets were prepared for analysis by elution of a colour layer with $50 \%(\mathrm{v} / \mathrm{v})$ methanol $(3-5 \mathrm{ml})$. The obtained solutions were filtered through GD/X Cellulose $0.2 \mathrm{~m}$ filters. Gelatin capsules were at first dissolved in $50 \%(\mathrm{v} / \mathrm{v})$ methanol (the same volume). The gelatin was then precipitated with acetonitrile $(2-4 \mathrm{ml})$. To prevent the passage of significant amount of gelatin to a solution, it was necessary to make elution of the dyes with $50 \%(\mathrm{v} / \mathrm{v})$ methanol. The content of the dyes in the samples prepared by this way was often at the Limit of Detection (LOD) level. For preconcentration of dyes and their separation from the residual matrix, dyes were isolated from eluates by using acidic aluminium oxide. Samples of the liquid pharmaceutical products (syrups, liquids) were analysed without another preparation step, or with only double dilution with water.

Using photoacoustic spectroscopy in the visible range of wavelengths to directly determine Sunset Yellow (E110) content in effervescent multivitamin tablets, the tablets were manually crushed into a fine powder form. Analysis was performed without further filtering or the use of an ultrasonic bath. To determine the dye content by conventional spectrophotometry, a mass of each powdered tablet was weighed and dissolved in $30 \mathrm{ml}$ of deionized water and then diluted to $50 \mathrm{ml}$. After filtration, the cuvette with filtrate had to be held in an ultrasonic bath for $1 \mathrm{~min}$ to eliminate the presence of $\mathrm{CO} 2$ bubbles [25]. 
In one paper [7] authors have described a method for the quantitative determination of Tartrazine in dimetcarb tablets containing a yellow parent compound (dimethpramide). The sample was prepared by adding $25 \mathrm{ml}$ of water to 10 tablets in a $50 \mathrm{ml}$ measuring flask and the mixture was stirred until the disintegration of the tablets. Then, water was added to the mark and the solution was thoroughly stirred and filtered. To $5 \mathrm{ml}$ of the filtrate was added $5 \mathrm{ml}$ of concentrated $\mathrm{HCl}$ and the mixture was stirred and characterized by the optical density at $435 \mathrm{~nm}$ relative to a reference solution (in $10 \mathrm{~mm}$ optical cells).

Derivative spectrophotometric methods were developed for determining Ponceau 4R and Tartrazine in order to resolve their binary mixtures. The method permits the simultaneous determinations of these dyes in various samples [62].

Eight synthetic dyes (Amaranth, Brilliant Blue, Indigo Carmine, New Red, Ponceau 4R, Sunset Yellow, Tartrazine, Allura Red) were determined by high-performance ion chromatography (HPIC) on an anion-exchange analytical column with very low hydrophobicity and visible absorbance detection. Gradient elution with hydrochloric acidacetonitrile effected both the chromatographic separation of these dyes and the on-line clean-up of the analytical column, which was very advantageous for routine analysis. High-performance ion chromatography may be a solution to the chromatographic analysis for some water-soluble, organic analytes with strong hydrophobicity. The method has been applied to the determination of dyes in drinks and in instant drink powder [9].

From the possibilities of determinations mentioned above, HPLC is one of the most widely used methods nowadays. Generally, HPLC provides a separation of mixtures to component substances whereas a properly chosen detector allows for their identification and for determination of their content. The basis of separation is represented by differences in the affinity of the constituents to two phases (stationary and mobile). Dyes exhibit different adsorption affinity to the stationary phase due to differences in their mass, structural space, and presence of functional groups in a molecule [45].

The most commonly utilized mode in liquid chromatography is represented by reverse phase, where the stationary phase has moderate or no polarity and the mobile phase is strongly polar (e.g. tetrahydrofuran, acetonitrile, methanol, water, etc.) [72]. Liquid chromatography-based tech- niques are usually coupled with UV-VIS, mass spectrometry (MS) or photodiode array (PAD) detectors. Due to the high polarity of dyes, their elution times are very short. In such cases, the use of C18 ether columns usually increases the retention times, especially of the azo dyes group [33].

Further ion-pair high performance liquid chromatography (IP-HPLC) can also be carried out by means of using ion-pairing (hydrophobic ionic) compounds such as ammonium acetate buffer, 1-hexadecyl trimethylammonium bromide etc., to the mobile phase to improve the separation and elution of the ionic target to be analysed [72]. The used contents of added solutions are usually above $0.1 \mathrm{~mol} . \mathrm{dm}^{-3}$ [51]. The most significant facts that must be taken into account during the choice of analytic conditions are the hydrophobic properties of dyes and the presence of acidic groups in their structures. As a result of the reaction between the sample and eluent, neutral ionic pairs are formed and are separated chromatographically in the reversed phase system. Another way is the preparation of samples which enables it to conduct the analysis on ionic exchanger or the modification of mobile phase to obtain an ion-exchanger. When the ionic compound is not present, elution times of some dyes (e.g. Tartrazine, Ponceau 4R, Indigo Carmine) are very short. The addition of an ionic agent results in increasing retention time of compounds with acidic functional groups in their structures. It is important for making the separation of dyes simultaneously. The $\mathrm{pH}$ value takes a considerable fundamental role in the quantification of dyes using the aforementioned method. In the case of using a column with silica gel, the $\mathrm{pH}$ value should be within the range 4-6 because of low hydrolytic gel stability [45].

In most of liquid chromatography methods, various organic solvents are used. Their negative influence on the environment and human health provides a basis for using "green methods" which are in full compliance with the principles of "Green chemistry". One of them is using a surfactant solution Triton X-100 (4-(1,1,3,3-tetramethylbutyl)phenyl-polyethylene glycol) as a mobile phase. This compound changes the polarity of water and disposition of the C18 column, which becomes more polar, whereas charges of dyes molecules are steadied. Brilliant Blue, Sunset Yellow and Tartrazine had been analysed by applying the above described method. The optimal concentration of Triton X-100 should be in the range of $0.25-1 \%$. On the one hand, too low a concentration of surfactant results in incorrect preparation of a column; on the other hand, too 
high of a concentration causes imprecise separation and quantitative determination of mixture compounds. The $\mathrm{pH}$ value should be equal to 7 . Below this value, some peaks disappeared. The addition of the phosphate buffer was necessary for a reliable analysis. The charges of buffer constituents balance the charges of dyes molecules. Applying this method, the analysis is completed in $8 \mathrm{~min}$ using $15 \mathrm{mg}$ surfactant and $38.8 \mathrm{mg}$ phosphate buffer [69].

High performance ion chromatography (HPIC) can also be used for dye analysis. It involves the use of specific columns filled in resins with functional groups which have constant charge bounded ions. In theory, HPIC is not suitable for organic, multivalent and hydrophobic ions because of strong bonding with the stationary phase. Due to this fact, their elution takes a long time. The use of an anion exchange column that has mild hydrophobicity and acidic eluent is required for this purpose $[9,45]$.

\section{CONCLUSIONS}

In the production of pharmaceuticals different additives that contribute to the formation of the actual drug form or its appearance are used. Various natural or synthetic dyes are used primarily to ensure the appearance and the ability to distinguish the individual drugs. These compounds have different chemical compositions and may interact in different ways with the human body. The safety of dyes used in foodstuffs and pharmaceutical products are assessed by the European Food Safety Authority (EFSA). Most recently in 2008, the safe use of synthetic dyes and ADI values were revised. Based on the available clinical studies and literature, EFSA stated that it is unlikely that these compounds have significant adverse impacts on human health during normal consumption. However, it is known that most studies are focused on the effect of only one dye and the possible combined impact of several dyes from different sources has not been examined. Some investigations point to the increasing consumption of products containing colouring agents. It is particularly evident especially among children. Recently, it has been found that certain dyes have the ability to bind to human serum albumin. This fact has the potential of leading towards the possibility of adverse toxic impacts. The problem is the fact that globally there is no uniformity in the rules relating to the use of dyes in the pharmaceutical field and also in foodstuffs. It often happens that in one country the dye is forbidden and in another it is permitted. Considering this, it is necessary to pay very close attention to the issue of the use of dyes in pharmaceutical products and medicines, and it is necessary to take into account the results of studies focused on pharmacological, neurological and other effects that dyes or their mixtures may have. An essential task is the need for the unification of legislation related to this issue on a global basis.

\section{REFERENCES}

1. Alghamdi, A.H., Alshammery, H.M., Abdalla, M.A., Alghamdi, A.F., 2009: Determination of Carmine Food Dye (E120) in foodstuffs by stripping voltammetry. J. AOAC Int., 92, 1454-1459.

2. Allam, K. V., Kumar, G., 2011: Colorants - the cosmetics for the pharmaceutical dosage forms. Int. J. Pharm. Pharm. Sci., 3, 13-21.

3. Amchova, P., Kotolova, H., Ruda-Kucerova, J., 2015: Health safety issues of synthetic food colorants. Regul. Toxicol. Pharmacol., 73, 914-922.

4. American Academy of Pediatrics, Committee on Drugs, 1997: Inactive ingredients in pharmaceutical products: Update. Pediatrics, 99, 268-278.

5. Ashkenazi, P., Yarnitzky, Ch., Cais, M., 1991: Determination of synthetic food colours by means of a novel sample preparations system. Anal. Chim. Acta, 248, 289-299.

6. Attokaran, M., 2011: Natural Food Flavours and Colorants. Wiley-Blackwell, 39.

7. Bagirova, V.L., Mitkina, L.I., 2003: Determination of Tartrazine in drugs. Pharm. Chem. J., 37, 558-559.

8. Chanlon, S., Joly-Pottuz, L., Chatelut, M., Vittori, O., Cretier, J. L., 2005: Determination of Carmoisine, Allura red and Ponceau $4 \mathrm{R}$ in sweets and soft drinks by differential pulse polarography. J. Food Compos. Anal., 18, 503-515.

9. Chen, Q. Ch., Mou, S. F., Hou, X. P., Riviello, J. M., Ni, Z.M., 1998: Determination of eight synthetic food dyes in drinks by high-performance ion chromatography. J. Chromatogr., A, $827,73-81$.

10. Choi, C. K., Dong, M. W., 2005: Chapter 5 - Sample preparation for HPLC analysis of drug products. In Ahuja, S., Dong, M. W.: Handbook of Pharmaceutical Analysis by HPLC. Elsevier, United Kingdom, 123-144.

11. Codex Alimentarius, 1962: http://www.fao.org/fao-who-codexalimentarius/about-codex/en/ (accessed 05.04.16). 
12. Combeau, S., Chatelut, M., Vittori, O., 2002: Identification and simultaneous determination of Azorubin, Allura red and Ponceau $4 \mathrm{R}$ by differential pulse polarography: application to soft drinks. Talanta, 56, 115-122.

13. Commission Directive 95/45/EC, 1995: Laying down specific purity criteriaconcerning colours for use in foodstuffs, OJEC L226, 1.

14. Commission Regulation 1333/2008, 2008: On food additives, OJEC L354, 16.

15. Commission Regulation 257/2010, 2010: Setting up a programme for the re-evaluation of approved food additives in accordance with Regulation (EC) No. 1333/2008 of the European Parliament and of the Council on food additives, OJEC L80, 19.

16. Commission Regulation 232/2012, 2012: Amending Annex II to Regulation (EC) No. 1333/2008 of the European Parliament and of the Council as regards the conditions of use and the use levels for Quinoline Yellow (E 104), Sunset Yellow FCF/Orange Yellow S (E 110) and Ponceau 4R, Cochineal Red A (E 124), OJEC L78, 1.

17. Council Directive 2645/62, 1962: On the approximation of the rules of the Member States concerning the colouring matters authorized for use in foodstuffs intended for human consumption, OJEC 2645/62, 279.

18. Council Directive 78/25/EEC, 1978: On the approximation of the laws of the Member States relating to the colouring matters which may be added to medicinal products, OJEC L11, 18 .

19. Council Directive 94/36/EC, 1994: On colours for use in foodstuffs, OJEC L237, 13.

20. Council Directive 2009/35/EC, 2009: On the colouring matters which may be added to medicinal products, OJEC L109, 10.

21. Council Regulation 178/2002, 2002: Laying down the general principles and requirements of food law, establishing the European Food Safety Authority and laying down procedures in matters of food safety, OJEC L31, 1.

22. de Boer, L., 2014: Biotechnological production of colorants. Adv. Biochem. Eng. Biotechnol., 143, 51-89.

23. Dipalma, J. R., 1990: Tartrazine sensitivity. Am. Fam. Physician., 42, 1347-1350.

24. Downham, A., Collins, P., 2000: Colouring our foods in the last and next millennium. Int. J. Food Sci. Tech., 35, 5-22.

25. Dóka, O., Bicanic, D., Ajtony, Z., Koehorst, R., 2005: Determination of sunset yellow in multi-vitamin tablets byphotoacoustic spectroscopy and a comparison with alternative methods. Food Addit. Contam., 22, 503-507.
26. EFSA, 2009a: Scientific opinion on the re-evaluation of Quinoline Yellow (E 104) as a food additive. EFSA J., 7, 1329.

27. EFSA, 2009b: Panel on food additives and nutrient sources added to food, scientific opinion on the re-evaluation of Sunset Yellow FCF (E 110) as a food additive. EFSA J., 7, 1330.

28. EFSA, 2009c: Scientific opinion on the re-evaluation of Azorubine/Carmoisine (E 122) as a food additive. EFSA J., 7, 1332.

29. EFSA, 2010a: Scientific opinion on the appropriateness of the food azo-colours Tartrazine (E 102), Sunset Yellow FCF (E 110), Carmoisine (E 122), Amaranth (E 123), Ponceau 4R (E 124), Allura Red AC (E 129), Brilliant Black BN (E 151), Brown FK (E 154), Brown HT (E 155) and Litholrubine BK (E 180) for inclusion in the list of food ingredients set up in Annex IIIa of Directive 2000/13/EC. EFSA J., 8, 1778.

30. EFSA, 2010b: Scientific opinion on the reevaluation of Brilliant Blue FCF (E 133) as a food additive. EFSA J., 8, 36.

31. European Medicines Agency, 2007: Guideline on excipients in the dossier for application for marketing authorisation of a medicinal product: http://www.ema.europa.eu/docs/ en_GB/document_library/Scientific_guideline/2009/09/ WC500003382.pdf (accessed 05.04.16).

32. Fallico, B., Chiappara, E., Arena, G., Ballistreri, E., 2011: Assessment of the exposure to Allura red colour from the consumption of red juice-based and red soft drinks in Italy. Food Addit. Contam., 28, 1501-1515.

33. Gosetti, F., Frascarolo, P., Mazzucco, E., Gianotti, V., Bottaro, M., Gennaro, M.C., 2008: Photodegradation of E110 and E122 dyes in a commercial aperitif: A high performance liquid chromatography-diode array-tandem mass spectrometry study. J. Chromatogr., A, 1202, 58-63.

34. Grzelewska-Rzymowska, I., Szmidt, M., Kowalski, M.L., Roźniecki, J., 1986: Sensitivity and tolerance to tartrazine in aspirin-sensitive asthmatics. Allergol. Immunopathol., 14, $31-36$.

35. http://www.codexalimentarius.net/gsfaonline/docs/CXS_192e. pdf (accessed 05.04.16).

36. Ishikawa, F., Shigeoka. S., Nagashima, M., Takahashi, M., Kamimura, H., 2003: Simultaneous determination of eleven dyes and their aluminum lakes in drugs. J. AOAC Int., 86, 215-221.

37. Jaworska, M., Szulinska, Z., Wilk, M., Anuszewska, E., 2005: Separation of synthetic food colourants in the mixed micellar system application to pharmaceutical analysis. J. Chromatogr., A, 1081, 42-47.

38. Kanarek, R. B., 2011: Artificial food dyes and attention deficit hyperactivity disorder. Nutr. Rev., 69, 385-391. 
39. Kaur, A., Gupta, U., 2014: Identification and determination of binary mixtures of synthetic dyes with $\mathrm{Cr}$ (III) complexation in food stuffs and pharmaceutical samples by high performance liquid chromatography. Indian Journal of Pharmaceutical Science and Research, 4, 49-52.

40. Khanavi, M., Hajimahmoodi, M., Ranjbar, A. M., Oveisi, M. R., Ardekani, M. R.S., Mogaddam, G., 2012: Development of a green chromatographic method for simultaneous determination of food colorants. Food Analytical Methods, 5, 408-415.

41. Khehra, M.S., Saini, H.S., Sharma, D.K., Chadha, B.S., Chimni, S.S., 2006: Biodegradation of azo dye CI Acid Red 88 by an anoxic-aerobic sequential bioreactor. Dyes Pigm., 70 , $1-7$.

42. Kim, S. H., Suk, E. H., Kil, S. H., Hahm, K. D., Hwang, J.H., 2011: Hypotension in patients administered indigo carmine containing impurities - A case report. Korean J. Anesthesiol., $61,435-438$

43. Kirschbaum, J., Krause, C., Pfalzgraf, S., Brückner, H., 2003: Development and Evaluation of an HPLC-DAD. Method for determination of synthetic food dyes. Chromatographia, 57, 115-119.

44. Kučerová, J., Kotolová, H., 2013: Toxicity of dyes used in medical preparations (In Czech). Prakt. Lekáren., 9, 83-89.

45. Kucharska, M., Grabka, J., 2010: A review of chromatographic methods for determination of synthetic food dyes. Talanta, 80, 1045-1051.

46. Lim, H. S., Choi, J. Ch., Song, S. B., Kim, M., 2014: Quntitative determination of carmine in foods by high-performance liquid chromatography. Food Chem., 158, 521-526.

47. Liu, Y.M., Yu, Q., Sun, L., Wang, S., 2006: Determination of synthetic colorant contents in officinal capsule. Chin. Pharm. J., 41, 303-305.

48. Macioszek, V.K., Kononowicz, A.K., 2004: The evaluation of the genotoxicity of two commonly used food colours: Quinoline Yellow (E 104) and Brilliant Black BN (E 151). Cell Mol. Biol. Lett., 9, 107-122.

49. Materiienko, A.S., Grudko, V. A., Georgiyants, V.A., 2014: Development of methods for determining Tartrazine and Carmoisine as part of shell of tablets "NITROXOLINE" (In Russian). Management, Economy and Quality Assurance in the Pharmacy, 1, 10-14.

50. McCann, D., Barrett, A., Cooper, A., Crumpler, D., Dalen, L., Grimshaw, K., et al., 2007: Food additives and hyperactive behaviour in 3-year-old and 8/9-year-old children in the community: a randomised, double-blinded, placebo-controlled trial. Lancet, 370, 1560-1567.
51. Minioti, K.S., Sakellariou, Ch.F. Thomaidis, N.S., 2007: Determination of 13 synthetic food dyes in water-soluble foods by reversed-phase high-performance liuid chromatography coupled with diode-array detector. Anal. Chim. Acta, $583,103-110$.

52. Moldoveanu, S. C., David, V., 2015: Chapter 2 - The role of sample preparation. In Moldoveanu, S. C., David, V.: Modern Sample Preparation for Chromatography. Elsevier, United Kingdom, 33-49.

53. Mpountoukas, P., Pantazaki, A., Kostareli, E., Christodoulou, P., Kareli, D., Poliliou, S., 2010: Cytogenetic evaluation and DNA interaction studies of the food colorants amaranth, erythrosine and tartrazine. Food Chem. Toxicol., 48, 29342944.

54. Nagaraja, T.N., Desiraju, T., 1993: Effects of chronic consumption of metanil yellow by developing and adult rats on brain regional levels of noradrenaline, dopamine and serotonin, on acetylcholine esterase activity and on operant conditioning. Food Chem. Toxicol., 31, 41-44.

55. National Toxicology Program, U.S., 1997: Toxicology and Carcinogenesis Studies of D\&C Yellow No. 11 (CAS no. 8003-22-3) in F344/N rats (feed studies). Natl. Toxicol. Program Tech. Rep. Ser., 463, 1-190.

56. Newsome, A.G., Culver, C.A., van Breemen, R.B., 2014: Nature's palette: the search for natural blue colorants. J. Agric. Food Chem., 62, 6498-6511.

57. Ni, Y., Gong, X., 1997: Simultaneous spectrophotometric determination of mixtures of food colorants. Anal. Chim. Acta, 354, 163-171.

58. Nickerson, B., 2011: Chapter 1-Properties that impact sample preparation and extraction of pharmaceutical dosage forms. In Nickerson, B.: Sample Preparation of Pharmaceutical Dosage Forms (Challenges and Strategies for Sample Preparation and Extraction). Springer, USA, 3-20.

59. Podczeck, F., Jones, B.E., 2004: Pharmaceutical Capsules, 2nd edn., Pharmaceutical Press, 66-67.

60. Ronald, A., Simon, M.D., 2003: Adverse reactions to food additives. Curr. Allergy Asthma Rep., 3, 62-66.

61. Rowe, R.C., Sheskey, P. J., Quinn, M.E., 2009: Chapter Coloring agents. In Rowe, R. C., Sheskey, P. J., Quinn, M. E.: Handbook of Pharmaceutical Excipients, 6th edn., Pharmaceutical Press and American Pharmacists Association, USA, 189-196.

62. Sayar, S., Özdemir, Y., 1997: Determination of Ponceau 4R and Tartrazine in various samples by derivative spectrophotometric methods. Turk. J. Chem., 2, 182-187. 
63. Sayar, S., Özdemir, Y., 1998: First-derivative spectrophotometric determination of ponceau 4R, Sunset Yellow and Tartrazine in confectionery products. Food Chem., 61, 367-372.

64. Sindhu, P.R., Bagya, L. J., Surya, P. R., 2011: Estimation of synthetic colorant Tartrazine in food stuff and formulations and effect of colorant on the protein binding of drugs. Int. J. Pharm. Ind. Res., 1, 141-152.

65. Tabar, A. I., Acero, S., Arregui, C., Urdánoz, M., Quirce, S., 2003: Asthma and allergy due to carmine dye. An. Sist. Sanit. Navar., 26, 65-73.

66. Timberlake, C.F., Bridle, P., 1980: In Walford, J. (Ed.): Developments in Food Colours-1. London, Applied Science Publishers Ltd., 115-149.

67. Tsuda, S., Murakami, M., Matsusaka, N., Kano, K., Taniguchi, K., Sasaki, Y. F., 2001: DNA damage induced by red food dyes orally administered to pregnant and male mice. Toxicol. Sci., 61, 92-99.

68. Üstün Özgür, M., Koyuncu, İ., 2002: The simultaneous determination of Quinoline Yellow (E-104) and Sunset Yellow (E-110) in syrups and tablets by second derivative spectrophotometry. Turk. J. Chem., 26, 501-508.
69. Vidotti, E. C., Costa, W. F., Oliveira, C.C., 2006: Development of a green chromatographic method for determination of colorants in food samples. Talanta, 68, 516-521.

70. Vlase, L., Muntean, D., Cobzac, S. C., Filip, L., 2014: Development and validation of an HPLC-UV method for determination of synthetic food dyes. Re. Roum. Chim., 59, 719-725.

71. Wu, T.T., Chang, Y.Ch., Lee, J.M., Hung, M.H., 2015: Anaphylactic reaction to patent blue $\mathrm{V}$ used in preoperative computed tomography-guided dye localization of small lung nodules. JFMA, 1-2.

72. Yamjala, K., Nainar, M.S., Ramisetti, N. R., 2016: Methods for the analysis of azo dyes employed in food industry - A review. Food Chem., 192, 813-824.

73. Yilmaz, U.T., Ergun, F., Yilmaz, H., 2014: Determination of the food dye carmine in milk and candy products by differential pulse polarography. J. Food Drug Anal., 22, 329-335.

74. Yoshioka, N., Ichihashi, K., 2008: Determination of 40 synthetic food colours in drinks and candies by high-performance liquid chromatography using a short column with photodiode array detection. Talanta, 74, 1408-1413.

Received March 21, 2017

Accepted July 13, 2017 